\title{
A New Reclassification in International Container Transport Market Based on the Impact of "One Belt And One Road" Initiative
}

\author{
Guo-Ya Gan \\ College of Auditing and Evaluation, Nanjing Audit University, Nanjing, PR China \\ Jui-Yuan Su \\ Department of New Media and Communication Administration, Ming Chuan University, Taipei, Taiwan, \\ rysu@mail.mcu.edu.tw
}

Follow this and additional works at: https://jmstt.ntou.edu.tw/journal

\section{Recommended Citation}

Gan, Guo-Ya and Su, Jui-Yuan (2021) "A New Reclassification in International Container Transport Market Based on the Impact of "One Belt And One Road" Initiative," Journal of Marine Science and Technology. Vol. 29: Iss. 1, Article 2. DOI: $10.51400 / 2709-6998.1001$

Available at: https://jmstt.ntou.edu.tw/journal/vol29/iss1/2

This Research Article is brought to you for free and open access by Journal of Marine Science and Technology. It has been accepted for inclusion in Journal of Marine Science and Technology by an authorized editor of Journal of Marine Science and Technology. 


\title{
A New Reclassification in International Container Transport Market Based on the Impact of "One Belt And One Road" Initiative
}

\author{
Guo-Ya Gan ${ }^{\mathrm{a}}$, Jui-Yuan Su ${ }^{\mathrm{b}, *}$ \\ ${ }^{\text {a }}$ College of Auditing and Evaluation, Nanjing Audit University, Nanjing, PR China \\ ${ }^{\mathrm{b}}$ Department of New Media and Communication Administration, Ming Chuan University, Taipei, Taiwan
}

\begin{abstract}
Research about the efficiency of the world's major container ports has always being one of the hot issues in container port market. Especially when the "One Belt And One Road" initiative proposed in 2013, the pattern of the world container market is constantly changing. This study aims at examining the changes in world's top 20 international container ports in the new era of the shipping competition market. In current study, we obtained the input data from the Containerization International Yearbook and the journal of commerce annual top world container ports. The concept of 'self-appraisal' and 'peer-appraisal' is proposed to construct a new reclassification for clustering world's top container ports into three different types. This study exposes that the world's international container market is showing a good development momentum by the impact of the "One Belt And One Road" initiative. However, the situations of inputs surplus or waste resources also exist in some top international container ports. According to characteristics and demands of each port, we put forward some corresponding recommendations with which the operators can adjust their operations and marketing strategies.
\end{abstract}

Keywords: International container ports, Peer-appraisal, Cross-efficiency, Data envelopment analysis (DEA), "One Belt And One Road" initiative

\section{Introduction}

$\mathrm{U}$ nder the background of rapid developments in modern industrialization and economic globalization, international trade around the world has to face serious challenges. What's more, it has more strongly correlated with the development of countries' business economy [1]. In China, for example, with second largest economy in the world, international trade absolutely plays a key role in the process of its economic growth, especially container transportation. According to the Containerization International Yearbook, container throughput of Chinese ports has expanded over threefold from 2008 to 2018. The main international container ports in China have been at the forefront of world container market. Furthermore, the President Xi of China puts forward the cooperation initiatives of building the "new silk road economic belt" and the "21st century maritime silk road" in 2013, namely the "One Belt And One Road" initiative, which actively developing the economic cooperative partnership with the countries along this "belt and road", and jointly building a community of mutual political trust, economic integration and cultural inclusiveness $[2,3]$. Therefore, enhancing the level of international trade with high efficiency could lead 
to rapid economic growth around the world. Especially under the impact by the "One Belt And One Road" initiative, international investment and trade barriers are eliminating while the economic cooperation and international transportation trade are rapidly growing.

International trade can be divided into two main forms: shipping transportation and air transportation. The former one, with advantages of being low-cost, clean, and safe, occupies more market space in international trade and creates more profit potential. Shipping transport is the indispensable link to promote the national economic construction and development of the international community [4]. The unimpeded trade and the exploitation of trade potential are the foundations of the "One Belt And One Road" strategy. In the process of the expansion of China's export trade, the non-efficiency situation is significant. There is still plenty of room and potential opportunity to improve China's export trade in the future, which is also especially true for the other "One Belt And One Road" cooperative countries [5]. Nations with powerful global economies are usually committed to enhancing their container transport systems for changing the patterns of container transportation. They are aimed at boosting their national economies through the container industry. Ultimately, the container transport industry has become more and more convenient and smart. For port operators, they clearly understand individual control productivity, marketing, labor costs or the research capabilities of each port, especially those that cannot match the demands of the complex international competition environment [6]. Both of the managers and operators know that the rapid development of international container ports plays a crucial role in promoting the progress of national economic, but many problems facing by their ports have been restricting the practical improvement of the efficiency of the port's operating.

In today's society, the correlation between transport efficiency and productivity performance in international trade is more significant than ever, especially in some coastal states. A port's efficiency is an important determinant of shipping costs. If port efficiency could be improved from $25 \%$ to $75 \%$, shipping costs would be reduced by $12 \%$ [7]. And port efficiency plays an important contributor role to a nation's international competitiveness [8]. As the key window opening to the outside world, nation's container ports provide an important channel connecting the domestic and international markets, which has a strong supporting and pull effect on the development of the nation's economy. And most scientific attention in port studies centers is on deep-sea ports, in particular container ports [9]. However, for many container ports, there are still some deficiencies in the function of port's operating [10]. In recent years, many cities realize the role of container ports in economic development and thus continuously develop their construction. There is the phenomenon of repeated construction of ports in adjacent areas, which is easy to lead to the chaos of the competitive market. As well as the increasingly fierce homogenization competition, these ports would greatly reduce the cooperation between each other, and even cause malicious competition. To many existing container ports, their common business is mainly the transportation and the loading/unloading of goods. They lack the overall construction and operation strategic planning of ports, which cannot meet the requirements of economic globalization and modern development [11]. On the other hand, during the development process, the business model of conventional ports is relatively simple. Although they can meet their own domestic transportation demands, the port's lack of competitiveness in the international market has become increasingly prominent due to the continuous aging of port equipment. In the context of the economic globalization, if the cargo transportation still takes waterway as the main channel, and ignores the linkage and cooperation with other approaches, it is easy to lead to the improvement limitation of throughput and some defects such as cargo detention in ports [12]. Many container ports obtain some rich cargo resources all over the world by virtue of their geographical location or the preferential policies of the state. However, the backward loading or transportation capacity will not only cause the labor cost or time cost waste, but also seriously interfere with the economic construction and development. Thus, the world's major container ports are facing the challenge of the emergence of intelligent transformation to meet the social development in the new era. And the main operational goal for the major container ports is increasing productivity and reducing transportation cost in order to heighten their sustainability and operational efficiency.

Under the influence of the "One Belt And One Road" initiative, container ports have ushered in a new round of major development opportunities. As the transportation hub for resource allocation, the cost of container transportation is usually more advantageous than that of train transportation or air transportation. Especially, the construction cost of container ships is relatively economical, which has 
become the first choice for some "low cost and high weight" cargo transportation [3]. The "21st century maritime silk road" under the "One Belt And One Road" initiative starts from ports in east China and travels to Europe via Indonesia, the Indian Ocean, North Africa and the Suez Canal. This route connects Asia, South Africa, North Africa, the Middle East and Europe. The implementation of this policy will greatly alleviate the dependence on the Malacca Strait around the world, and greatly reduce the risk of being subject to human factors. With the increasing press of throughput, the connectivity and intelligent have become the most representative and key characteristics of modern international ports [13]. Promoted by the "One Belt And One Road" initiative, the development of $5 \mathrm{G}$, the Internet of Things (IOT) and some other technologies have helped some Chinese container ports make breakthroughs in differentiated services, including the inter-port interactions and seamless links with the port supply chain, which finally makes China dominate 7 of the Top 10 international container ports based on the annual throughput ranking. With the continuous implementation of "One Belt And One Road" initiative in China, it not only enhances the international competitiveness of Chinese ports and accelerates their intelligent upgrading, but also quietly has a certain impact on the competitive relationship in the world container shipping market.

Clearly, the key factor for gaining a competitive advantage, under complicated competitive environment, in the global container transportation industry is to adjust operational strategy in a timely manner in order to increase port efficiency. By understanding the new development level of container ports in the world and mastering the operation dynamics of the container market, port managers could implement more advantageous operating strategies and gain more potential opportunities. In addition, the outbreak of the new coronavirus "COVID-19" has spread around the world, which directly affects the sharp decline of the world's economies, and the traditional container transportation industry has also suffered. Hence, this study aims at providing a new reclassification of the world's Top 20 container ports in the new era of the shipping competition market and selecting the main container centres and regions for benchmarking in order to help inefficient ports find direction for improvement. Further, this study also hopes to explore the problem of uneven allocation of resources or waste of resources in the production process to ensure that the port can survive the crisis.

The structure of this paper is as follows: Section 2 reviews the literature about the DEA applications in different filed, especially in applying DEA model to evaluate the performance of the international container ports in recent years. Section 3 presents the methodology used in this study, including selfappraisal and peer-appraisal. The evaluation results will be chose as the key indicators for the clustering of the international container shipping market. Section 4 presents the results of an empirical study of world's top 20 international container ports in 2018, and some critical input and output variables are chosen for this study. According to the evaluation results, a new reclassification in the world's international container market is presented in Section 5, and the resource waste situation of each group is further analyzed. Finally, concluding remarks are summarized in Section 6.

\section{Literature review}

Performance evaluation usually can help an enterprise or organization enhance operating efficiency, and auxiliary enterprise managers to explore the potential problems during the operating process, which can provide some important reference basis for decision-making, the key support for organizational development, and the evaluation basis for the promotion of employees, etc. This work can also promote managers to comprehensively measure the economic benefits and the rationality of resource allocation in investment decisions, so as to avoid the waste of resources and the eventual loss of economic benefits of the enterprise. Data envelopment analysis (DEA) is defined as a mathematical tool to measure the relative efficiencies of peer decision making units (DMUs) with multiple inputs and outputs [14], which has drawn the attention by some scholars for the performance evaluation and spread to various fields. Based on the background of type-2 fuzzy model, Zhou et al., [15] propose one multi-objective DEA model to evaluate suppliers in supply chain management, and they demonstrate that their study can help managers to balance the social, environmental and economic factors when choosing the most sustainable suppliers. From the perspective of maritime navigation security, Gan et al., [16] evaluate the systematic patterns of Changjiang Maritime Safety Administration (MSA) in China and one construct one suitable assessment DEA model, and collision and foundering-based accidents are identified to be the most common varieties of marine accidents in the Changjiang River. In addition, Zhou et al., [17] propose a new DEA frontier model to improve the understanding of rebalancing strategy for investors, and the results can provide reference for constructing sustainable 
green funds and the investment recommendations. While Wegener and Amin, [18] focus the research on environmental issues about greenhouse gas (GHG) emissions. Applications in oil and gas industry are demonstrated in their research to explore the efficient approach for potential GHG emissions reductions. The related DEA applications have also covered some other research fields, such as health care, air transportation, education, finance, banking, energy, etc [19-23].

Generally, ports are the gathering points or hubs of land and sea transportation, which are also the distribution centers of industrial/agricultural products and the import/export materials of global trade. This industry is usually characterized by large investment scale and long construction period. Thus, the research issue related to port performance evaluation has always been one of the hot topics concerned by some scholars. To examine the influence of certain specific explanatory variables, Chang and Tovar, [24] propose one two-step approach to measure the productivity of port terminals in Peru and Chile. A DEA-Malmquist model in a metafrontier framework is used in the first stage to evaluate productivity efficiency while an ArellanoBond model is estimated in the following step. They explore that container bulk rate and private operation have positive contribution to the change of productivity while bulk rate and total factor productivity present the opposite influence. Through the combinations of DEA and Stochastic Frontier Analysis (SFA), Wiegmans and Witte, [25] focus on evaluating the influence efficiency of container terminal characteristics ant testing the different group of inputs and output variables. Design capacity in operations is selected to be the most significant difference between waterway container terminals and maritime terminals, while the yard, crane, terminal operating hours and terminal area are chose to be the key terminal investment resource. For exploring the sustainable development of different port city systems, Chen and Lam, [26] choose the contemporary data of 20 world-leading container port cities for their study. Combing a new proposed two-stage DEA approach to measure the relative efficiency, their research reveal the relative differences in different sustainable development level, which also point out the effectiveness of their current policies. Under the sanctions imposed on the Iranian port's operators, Zarbi et al., [1] analyze the port's operating performance and the relative efficiency through applying DEA models during the period from 2012 to 2018, and they find out that average efficiency of all ports have significantly decreased after this imposed sanction.
With the rapid development of economy, many problems such as the environmental pollution have also been arisen. Under the variable returns to scale (VRS), Sun et al., [27] propose a non-radial Directional Distance Function (DDF-DEA) model to consider the environmental factors in the operations of container ports. Their research points out that the average efficiency of all evaluated ports has been an obvious decline when environmental factors are considered. Further, port assets, berth quantity, and the geographical location are detected to have a significant effect on the environmental performance of port enterprises in China. While Lin et al., [28] intend to develop an inverse DEA model to measure the efficiency of container ports and evaluate the resource consumption through considering the undesirable outputs. They select 16 main container ports in China to examine the feasibility of the proposed model, and the evaluation results can help the decision makers with deeply insights into the resource optimization of their container ports. From the perspective of the circumstance of environmental control, non-environmental control and PM emission via inter-ports cooperation, Wang et al., [29] propose three DEA models to evaluate the environmental efficiency of 11 major container ports in China. Their research results real that container ports in the eastern China present the relative higher efficiency. Besides, the cooperation between container ports can help improve both expected output, but with the increase of PM emission standard, port cooperation will lose its original advantage.

Therefore, the DEA application in the field of international container ports has always been attracting the attention of scholars. Through the DEA model, scholars not only explore the potential risks or the waste of resources in the port operation, but also provide suggestions for the port managers to improve the operational strategy. However, the current research is usually focused on China or a single country, which ignores the effect caused by the implementation of the new "One Belt And One Road" initiative. From the global perspective, exploring the new pattern generated by the world centralized transportation market should be a meaningful research issue. Hence, combing with the 'self-appraisal' and 'peer-appraisal' approaches, this study hopes to construct a new reclassification for clustering top international container ports (i.e., benchmarking type, modesty type, and learning type). Further, in order to explore the situations of inputs surplus or waste resources exiting in the operating process, this study will re-measure strength and weakness of each evaluated container port by the proposed computations. 


\section{Methodology}

\subsection{Self-appraisal}

Charnes et al., [14] proposed a model to analysis the data efficiency of each DMU (decision making unit), published in European Journal of Operational Research. Supposed there were $m$ inputs and $s$ outputs. Let $y_{r j}$ and $x_{i j}$ (all positive) to be as the outputs and inputs of the $j$ th DMU, $u_{r}$ and $v_{i}$ are the variable weights to determine the solution of the evaluation model. Then, $E_{k}$ is the CCR efficiency of $k$ th DMU. In more precise form, CCR model is shown by following.

$$
\begin{array}{ll}
\max & E_{k}=\frac{\sum_{r=1}^{s} u_{r} y_{r k}}{\sum_{i=1}^{m} v_{i} x_{i k}} \\
& \quad \sum_{r=1}^{s} u_{r} y_{r j} \\
\text { s.t. } & \quad \sum_{i=1}^{m} v_{i} x_{i j} \\
& u_{r}, v_{i} \geq \epsilon>0, r=1, \ldots, n ;
\end{array}
$$

where denotes the non-Archimedean parameter. Model (1) is a non-linear programming. By the Charnes-Cooper transformation, model (1) can be calculated by the linear programming with the following model:

$$
\begin{array}{ll}
\max & E_{k}=\sum_{r=1}^{s} u_{r} y_{r k} \\
\text { s.t. } & \frac{\sum_{r=1}^{s} u_{r} y_{r j}}{} \quad \sum_{i=1}^{m} v_{i} x_{i j} \\
& \sum_{i=1}^{m} v_{i} x_{i k}=1, j=1, \ldots, n ; \\
& u_{r}, v_{i} \geq \epsilon>0, r=1, \ldots, m ;
\end{array}
$$

CCR model is the constant returns to scale, in other words, when proportional increase the investment, the growth rate of output will follow the same proportion. Based on the CCR model, Banker et al., [30] combined the Shephard's distance function concept, and introduced a new separate variable to make it possible to determine whether operations were conducted in regions of increasing, constant or decreasing returns to scale (both in multiple input and output situations).

$$
\begin{array}{ll}
\max & E_{k}=\sum_{r=1}^{s} u_{r} y_{r k}-u_{o k} \\
\text { s.t. } \quad & \frac{\sum_{r=1}^{s} u_{r} y_{r j}-u_{o j}}{\sum_{i=1}^{m} v_{i} x_{i j}} \leq 1, j=1, \ldots, n \\
& \sum_{i=1}^{m} v_{i} x_{i k}=1, \mathbf{i}=1, \ldots, m ; \\
& u_{r}, v_{i} \geq \epsilon>0, r=1, \ldots, s, \mathbf{i}=1, \ldots, m .
\end{array}
$$

where $u_{o j}$ is the new separate variable for $j$ th DMU, with $h_{k}$ being the efficiency of $k$ th DMU in BCC model. BCC model is the variable returns to scale, in other words, the efficiency frontier of BCC model is mutative, contrasting to the constant one under CCR model. The efficiency frontier of CCR model is a ray passing through the origin while the one of $\mathrm{BCC}$ model is an arc enveloping with all the evaluation units. DMUs on the frontier line are defined as the "efficient". In order to explore the new ranking of top 20 container ports in the world, under this new type of changed shipping competition environment, we applied CCR model on this study.

\subsection{Peer-appraisal}

Both DEA-CCR and BCC efficiency can be called 'self-appraisal'. The optimal vectors are determined by each DMU, which could maximize their own efficiency. Although CCR model can distinguish each port's efficiency more clearly, but we couldn't just rely on a single index, even the result could be chose by itself, to provide a relatively objective and fair ranking for all the DMUs. In 1994, Doyle and Green developed the concept of 'cross-efficiency' and explained an intuitive understanding of cross-efficiency in the concept of 'peer-appraisal', in short words, which is an averaged value of evaluations calculated by peers. The cross-efficiency model is providing an aid to cluster gather the similar DMU more objectively and clearly.

The original concept of 'cross-efficiency' is proposed by Doyle and Green, [31]. They defined $u_{r k}$ (for $k$ 's $r$ th output) and $v_{i k}$ (for $k$ 's $i$ th input) as the advantage weights chose by DMU- $k$. And $y_{r j}$ is the $r$ th output of DMU- $j$ while the $x_{i j}$ is the $i$ th input of DMU- $j$. Then, $E_{k j}$ can be computed as the cross-efficiency of DMU- $j$, evaluated by the set of weights that DMU- $k$ has chosen:

$E_{k j}=\frac{\sum_{r=1}^{s} u_{r k} y_{r j}}{\sum_{i=1}^{m} v_{i k} x_{i j}}$ 
i.e., it is the weighted sum of outputs over the weighted sum of inputs. Then, the cross-efficiency DEA model can be formulated as:

$\max E_{k k}=\frac{\sum_{r=1}^{s} u_{r k} y_{r k}}{\sum_{i=1}^{m} v_{i k} x_{i k}}$

$$
\begin{array}{ll}
\text { s.t. } & E_{k j} \leq 1, j=1, \ldots, n ; \\
& u_{r k}, v_{i k} \geq \epsilon>0, r=1, \ldots, s, \mathbf{i}=1, \ldots, m .
\end{array}
$$

Doyle and Green, [31] indicate that the weights $v_{i k}$ and $u_{r k}$ would reduce the perceived usefulness of crossefficiency, which may not be unique in model (5) to maximize $E_{k k}$. So, they proposed the other goals to determine the unique solution of weights, which including two approaches named 'Aggressive Crossefficiency' (model (6)) and 'Benevolent Cross-efficiency' (model (7)):

$\min (n-1) E_{k}=\sum_{j \neq k} E_{k j}=\sum_{j \neq k} \frac{\sum_{r=1}^{s} u_{r k} y_{r j}}{\sum_{i=1}^{m} v_{i k} x_{i j}}$

s.t. $\quad E_{k j} \leq 1, j=1, \ldots, n$;

$$
\begin{gathered}
\sum_{i=1}^{m} v_{i k} x_{i k}=1, \mathrm{i}=1, \ldots, m \\
\sum_{r=1}^{s} u_{r k} y_{r k}-E_{k k} \cdot \sum_{i=1}^{m} v_{i k} x_{i k}=0, r=1, \ldots, s, \mathbf{i}=1, \ldots, m \\
u_{r k}, v_{i k} \geq \epsilon>0, r=1, \ldots, s, \mathbf{i}=1, \ldots, m
\end{gathered}
$$

At the same time, 'Benevolent Cross-efficiency' just benevolently changes the optimal value by maximizing the objective function for all evaluated DMUs:

$\max (n-1) E_{k}=\sum_{j \neq k} E_{k j}=\sum_{j \neq k} \frac{\sum_{r=1}^{s} u_{r k} y_{r j}}{\sum_{i=1}^{m} v_{i k} x_{i j}}$

s.t. $\quad E_{k j} \leq 1, j=1, \ldots, n$;

$$
\begin{gathered}
\sum_{i=1}^{m} v_{i k} x_{i k}=1, \mathbf{i}=1, \ldots, m ; \\
\sum_{r=1}^{s} u_{r k} y_{r k}-E_{k k} \cdot \sum_{i=1}^{m} v_{i k} x_{i k}=0, r=1, \ldots, s, \mathbf{i}=1, \ldots, m ; \\
u_{r k}, v_{i k} \geq \epsilon>0, r=1, \ldots, s, \mathbf{i}=1, \ldots, m .
\end{gathered}
$$

However, instead of the result leads to a nonlinear fractional program by model (6), Sexton et al., [32] suggested an adequate surrogate to minimize the sum of numerators of the fractions minus the sum of the denominators.

$$
\begin{aligned}
\min \psi_{k} & =\sum_{j \neq k}\left(\sum_{r=1}^{s} u_{r k} y_{r j}-\sum_{i=1}^{m} v_{i k} x_{i j}\right) \\
& =\sum_{r=1}^{s}\left(u_{r k} \cdot \sum_{j \neq k} y_{r j}\right)-\sum_{i=1}^{m}\left(v_{i k} \cdot \sum_{j \neq k} x_{i j}\right)
\end{aligned}
$$

s.t. $\quad E_{k j} \leq 1, j=1, \ldots, n$;

$$
\begin{gathered}
\sum_{i=1}^{m} v_{i k} x_{i k}=1, \mathbf{i}=1, \ldots, m ; \\
\sum_{r=1}^{s} u_{r k} y_{r k}-E_{k k} \cdot \sum_{i=1}^{m} v_{i k} x_{i k}=0, r=1, \ldots, s, \mathbf{i}=1, \ldots, m ; \\
u_{r k}, v_{i k} \geq \epsilon>0, r=1, \ldots, s, \mathbf{i}=1, \ldots, m .
\end{gathered}
$$

As we move forward the $k$ th row of the matrix $E$ of cross-efficiencies, shown in Fig. 1, each entry $E_{k j}$ is the efficiency of $k$ accords to DMU- $j$, given the computed weighting scheme from the above (e.g., $E_{34}$ is the cross-efficiency accorded DMU-4 using DMU-3's weights). Simple efficiencies are the $E_{k k}$ in the leading diagonal, which is called 'self-appraisal.' And $e_{k}$ is the 'peer-appraisal' for each DMU- $k$. Both $A_{k}$ and $e_{k}$ are averaged without the leading diagonal in this study.

\section{Empirical study}

4.1. Data

In current study, the throughput data of the top 20 major international container ports around the world derive from the Alphaliner monthly monitor (2019). And investment resources for each container port, including port-by-port guide to container facilities, crane, handing equipment and traffic statistics for the container terminals, are collected from Containerization International Yearbook. The top 20 international container ports (Country/region) are including: Shanghai (China), Singapore (Singapore), Shenzhen (China), Ningbo-Zhoushan (China), Guangzhou (China), Busan (Korea), Hong Kong (China), Qingdao (China), Tianjin (China), Dubai (United Arab Emirates), Rotterdam (Netherland), Port Klang (Malaysia), Antwerp (Belgium), Kaohsiung (Taiwan), Xiamen (China), Dalian (China), Los Angeles (USA), Tanjung Pelepas (Malaysia), Hamburg (Germany) and Long Beach (USA), respectively. 


\begin{tabular}{|c|c|c|c|c|c|c|c|}
\hline \multirow[t]{2}{*}{ DMUs } & \multicolumn{6}{|c|}{ Rated DMU } & \multirow{2}{*}{$\begin{array}{l}\text { Averaged } \\
\text { appraisal of } \\
\text { peers }\end{array}$} \\
\hline & 1 & 2 & 3 & 4 & 5 & 6 & \\
\hline 1 & $\mathbf{E}_{11}$ & $\mathrm{E}_{12}$ & $\mathrm{E}_{13}$ & $\mathrm{E}_{14}$ & $\mathrm{E}_{15}$ & $\mathrm{E}_{16}$ & $\mathrm{~A}_{1}$ \\
\hline 2 & $E_{21}$ & $\mathbf{E}_{22}$ & $\mathrm{E}_{23}$ & $\mathrm{E}_{24}$ & $\mathrm{E}_{25}$ & $\mathrm{E}_{26}$ & $\mathrm{~A}_{2}$ \\
\hline 3 & $E_{31}$ & $E_{32}$ & $\mathbf{E}_{33}$ & $E_{34}$ & $E_{35}$ & $E_{36}$ & $\mathrm{~A}_{3}$ \\
\hline 4 & $\mathrm{E}_{41}$ & $E_{42}$ & $\mathrm{E}_{43}$ & $\mathbf{E}_{44}$ & $\mathrm{E}_{45}$ & $\mathrm{E}_{46}$ & $\mathrm{~A}_{4}$ \\
\hline 5 & $\mathrm{E}_{51}$ & $\mathrm{E}_{52}$ & $\mathrm{E}_{53}$ & $\mathrm{E}_{54}$ & $\mathbf{E}_{55}$ & $\mathrm{E}_{56}$ & $\mathrm{~A}_{5}$ \\
\hline 6 & $E_{61}$ & $E_{62}$ & $E_{63}$ & $E_{64}$ & $E_{65}$ & $E_{66}$ & $\mathrm{~A}_{6}$ \\
\hline & $e_{1}$ & $\mathrm{e}_{2}$ & $e_{3}$ & $\mathrm{e}_{4}$ & $\mathrm{e}_{5}$ & $\mathrm{e}_{6}$ & \\
\hline
\end{tabular}

Fig. 1. Matrix of cross-efficiencies for Data Envelopment Analysis involving six DMUs.

\subsection{Input and output variables}

From the literature review, three major input categories consist of labor input, land/capital/ equipment input and others, while the main output variables including actual throughput, service level output and others. In previous studies, many scholars have conducted performance evaluations of container ports from diverse perspectives pertaining to port operational inputs. Hung et al., [33] evaluated port efficiency using container gantry, berth, quay length, and terminal area as input variables, while Haralambides and Gujar, [34] chose the same inputs along with indicators of straddle carriers and terminal area for their research. Competitive advantage of container ports relies on the cheap labor, land and other resources, DíazHernández et al., [35] select the labor cost and capital cost as the original input for their research. $\mathrm{Yu}$ and Chen, [36] take into account the facts of fuel cost, handling cost and vessel capacity to evaluate the operating performance of Taiwan's container industry. Besides, Chen and Lam, [26] choose the terminal area, berth length, and number of quay crane as their research input variables. To sum up, this study selects container berth, total quay length and terminal area as input indicators, and some variables have been combined to create a new indicator-pieces of port equipment-which includes the number of quayside gantries, yard gantries rail-mounted and rubber-typed, yard/terminal tractors, and yard chassis/trailers.

Most of the literature associated with port performance evaluation reveals that the number of containers or cargo throughput is one of key indicators that are used as an output variable (Hung et al. (2010; $[10,12,24,26]$. Therefore, the annual throughput of container cargoes is chose to be the unique and critical output in this study.

\subsection{Evaluation results}

Statistical information of input and output variables selected for our study is shown in Table 1. For each variable, no matter input or output variables, the differentiation of each international container port is obvious. Among them, the number of annual container throughput presents the maximum of standard deviation, followed by the total quay length and the number of pieces of equipment. In terms of annual container throughput ranking, the performance of port ranked in the first is approximately six times as the last one. The minimum of standard deviation belongs to the container berth. To explore the correlations of input and output variables in the current study, we find all the input

Table 1. Statistical information of input and output variables.

\begin{tabular}{|c|c|c|c|c|c|}
\hline \multirow[t]{2}{*}{ Statistics } & \multicolumn{2}{|l|}{ Input } & \multirow[b]{2}{*}{ Total quay length (m) } & \multirow[b]{2}{*}{ Terminal area (ha) } & \multirow{2}{*}{$\frac{\text { Output }}{\text { No. of containers (TEU) }}$} \\
\hline & Container Berth & No. of pieces of equipment ${ }^{a}$ & & & \\
\hline Max & 75 & 1508 & 16,407 & 1320 & $42,010,000$ \\
\hline Min & 12 & 122 & 3951 & 48 & $8,090,000$ \\
\hline Average & 30.90 & 473.75 & 9126.40 & 478.02 & $17,421,500$ \\
\hline SD & 16.07 & 428.78 & 4196.00 & 333.68 & $9,338,687$ \\
\hline
\end{tabular}

Note: ${ }^{\text {a }}$ No. of pieces of equipment = Number of quayside gantries, yard gantries (rail-mounted and rubber typed), yard/terminal tractors and yard chassis/trailer. 
variables show the positive correlation with the output. Meanwhile, this same situation also exists among the input variables themselves.

Table 2 summarizes the results of the evaluated Top 20 container ports under both self-appraisal and peer-appraisal approaches (detail matrix of cross-efficiencies is shown in Appendix I). As indicated in Table 2, most of container ports have obtained the satisfactory evaluation scores of selfappraisal, and more than half of them have obtained the efficiency value over 0.8 . In addition, six ports are evaluated as the relative efficient benchmark, in terms of Shanghai, Singapore, Ningbo-Zhoushan, Guangzhou, Qingdao, Tianjin, respectively. Obviously, under the influence of "One Belt And One Road" initiative implementation, the comprehensive strength of Chinese container ports still occupies the major position in the global international shipping market. The average efficiency score of Chinese

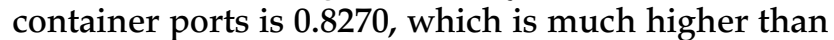
the value of the remaining world's Top 20 container ports (0.4717).

Besides, the evaluation results under the peerappraisal approach are shown in Column 4. Compere to self-appraisal, the efficiency values of all container ports are reduced. The highest score is obtained by the Ningbo-Zhoushan port, which is also a rising star in Chinese container ports in the recent years. Due to the geographical proximity of Ningbo and Zhoushan port, the homogenized competition between the two ports has greatly weakened their competitiveness in the competitive international container market and caused the waste of many resources. Under the promotion of "One Belt And One Road" initiative

Table 2. Results of self-appraisal and peer-appraisal.

\begin{tabular}{lllll}
\hline Container ports & Self-appraisal & Rank & Peer-appraisal & Rank \\
\hline Shanghai & 1.0000 & 1 & 0.6936 & 5 \\
Singapore & 1.0000 & 1 & 0.6414 & 6 \\
Shenzhen & 0.6954 & 9 & 0.5537 & 9 \\
Ningbo-Zhoushan & 1.0000 & 1 & 0.9630 & 1 \\
Guangzhou & 1.0000 & 1 & 0.7403 & 4 \\
Busan & 0.6548 & 10 & 0.4197 & 12 \\
Hongkong & 0.4866 & 14 & 0.3459 & 13 \\
Qingdao & 1.0000 & 1 & 0.8159 & 3 \\
Tianjin & 1.0000 & 1 & 0.8283 & 2 \\
Dubai & 0.3190 & 18 & 0.2167 & 17 \\
Rotterdam & 0.3418 & 16 & 0.2123 & 18 \\
Port Klang & 0.5067 & 13 & 0.2837 & 14 \\
Antwerp & 0.3395 & 17 & 0.2196 & 16 \\
Kaohsiung & 0.7015 & 8 & 0.5888 & 8 \\
Xiamen & 0.7989 & 7 & 0.6355 & 7 \\
Dalian & 0.5873 & 12 & 0.4573 & 11 \\
Los Angeles & 0.2874 & 19 & 0.1975 & 19 \\
Tanjung Peleas & 0.6541 & 11 & 0.5242 & 10 \\
Hamburg & 0.2539 & 20 & 0.1922 & 20 \\
Long Beach & 0.3598 & 15 & 0.2479 & 15 \\
\hline
\end{tabular}

implementation, they begin to share resources through recombination and configuration to achieve a dramatic increase in annual throughput. Followed by Tianjin and Qingdao ports, they also obtain the satisfactory performance with scores of 0.8283 and 0.8159 . It's important to note that these ports are one of the key pilot ports that China attaches importance to strengthening their intelligent transformation in the process of implementing the "One Belt And One Road" initiative. Therefore, it is clear that the Chinese government has made a very positive and significant contribution to enhance international competitiveness of its container ports through the implementation of "One Belt And One Road" initiative.

\section{Classification and analysis}

\subsection{Classification}

Quadrant diagrams can be used to clearly present the distribution of a port's performance, therefore, according to the evaluation in Table 2, this study applies the evaluation results of 'self-appraisal' as abscissa and the 'peer-appraisal (cross-efficiency)' as ordinate to construct a new classification of word's Top 20 container ports, as shown in Fig. 2.

- Benchmarking type: efficiency score of selfappraisal are equal to 1, while the cross-efficiency under peer-appraisal are larger than 0.6.

In this group, the efficiency of each DMU is relatively higher, in not only self-assessment but also relative-assessment, which can possibly be used as a benchmark for the other DMUs. In current study, Ningbo-Zhoushan, Tianjin, Qingdao, Guangzhou, Shanghai and Singapore are selected in this group.

- Modesty type: $0.5<$ efficiency score of selfappraisal $<0.8,0.4<$ cross-efficiency under peer-appraisal $<0.7$

In this group, the efficiency of each DMU in the relative-assessment is relatively higher, but the selfassessment is relatively lower, like in humble people. According to the results, Xiamen, Kaosiung, Shenzhen, Tangjung, Dalian, and Busan ports are gathered in this group.

- Learning type: efficiency score of self-appraisal is lower than 0.6, while the cross-efficiency under peer-appraisal is also lower than 0.5

In this group, not only is the efficiency of each port in the peer-assessment relatively lower but also the circumstance is identical in the self-assessment, 


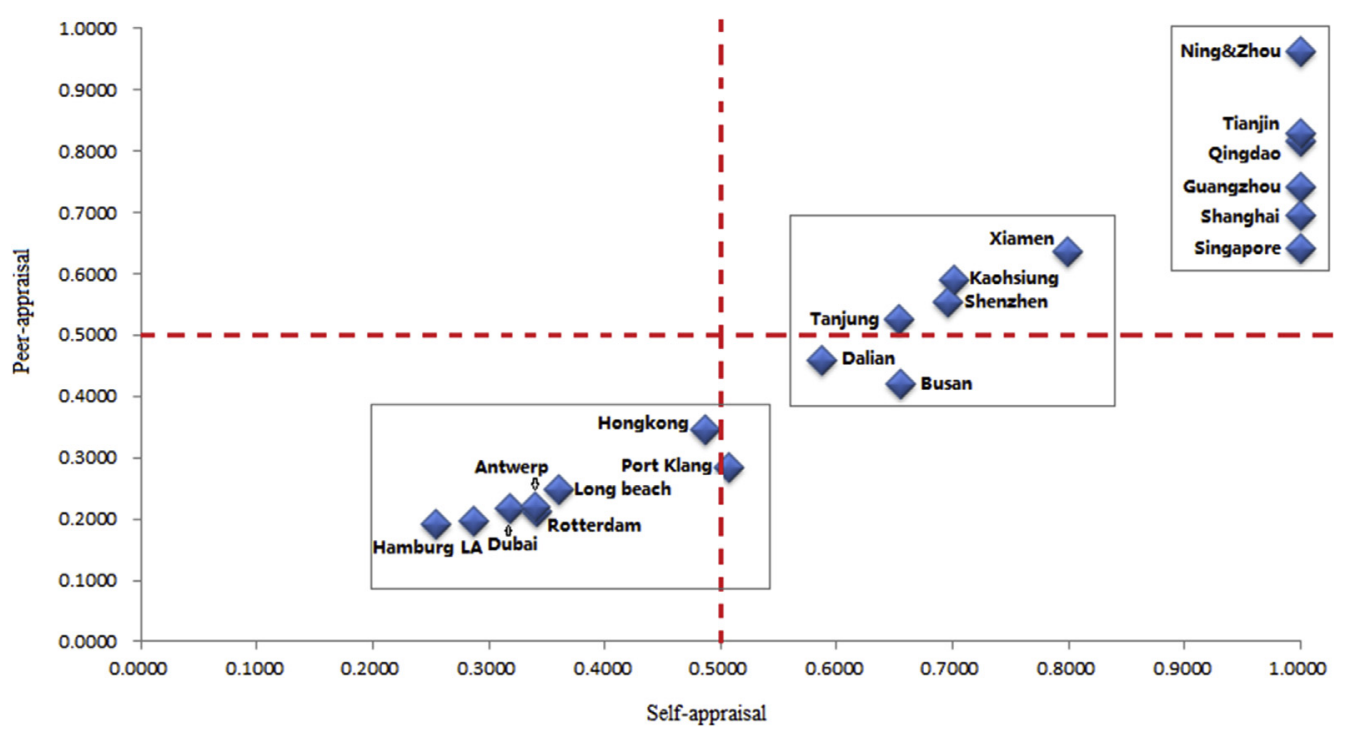

Fig. 2. A new reclassification for world's Top 20 international container ports.

which emphasizes that they need to enhance themselves more efficiently. Such as Hongkong, Port Klang, Long Beach, Antwerp, Rotterdam, Dubai, Los Angeles and Hamburg have the demands.

\subsection{Optimal adjustment analysis}

To managers, the significant decision reference information can not only help them to dig out the potential problems in the process of enterprise operation, but also provide them with the optimal adjustment amount analysis. And this valuable evaluation can help mangers more efficiently to save invested resources and avoid excessive waste. Due to the ports belongs to "Benchmarking Type" presenting the relative effectiveness, they construct the efficient frontier for all DMUs. In other words, their current operating is efficient and they don't need to change this situation. Thus, according to the new reclassification, this study just carries out the adjustment analysis for both "Modesty Type" and "Learning Type" based on the self-appraisal approach under the input-oriented, as shown in Table 3 and Table 4.
Under the self-appraisal, since the efficiency value of each port in "Benchmarking Type" is equal to 1, which indicates that their operation performance is relatively efficient. Hence, they do not need to reduce the investment resources. Meanwhile, it's important to mention that the optimal adjustment analysis for both "Modesty Type" and "Learning Type", which is based on the self-appraisal approach under the input-oriented. In other words, we hope to provide more targeted adjustment information for each port to achieve the efficient operating while the outputs keeping the current situation. Therefore, all outputs should not be changed and the optimal adjustment analysis is just suited for the input variable of each evaluated international container ports.

By comparing the analysis results of optimal adjustment quantities of these two groups, it is not difficult to find that the ratio of investment resources to be reduced in these two groups is completely different. To "Modesty Type", the number of pieces of equipment in the port obtains the highest proportion of the average optimal reduction, and the ratio presents to be $-44.95 \%$. However, the

Table 3. Optimal adjustment analysis for ports of Modesty Type.

\begin{tabular}{lllll}
\hline Container ports & Container Berth & No. of pieces of equipment & Total quay length (m) & Terminal area (ha) \\
\hline Shenzhen & $-30.46 \%$ & $-30.46 \%$ & $-37.06 \%$ & $-45.83 \%$ \\
Busan & $-34.52 \%$ & $-79.67 \%$ & $-34.52 \%$ & $-34.52 \%$ \\
Kaohsiung & $-34.45 \%$ & $-35.26 \%$ & $-29.85 \%$ & $-29.85 \%$ \\
Xiamen & $-45.59 \%$ & $-48.45 \%$ & $-20.11 \%$ & $-20.11 \%$ \\
Dalian & $-53.72 \%$ & $-41.27 \%$ & $-41.27 \%$ & $-41.27 \%$ \\
Tanjung Peleas & $-34.93 \%$ & $-34.59 \%$ & $-34.59 \%$ & $-44.07 \%$ \\
Average & $-38.95 \%$ & $-44.95 \%$ & $-32.90 \%$ & $-35.94 \%$ \\
\hline
\end{tabular}


Table 4. Optimal adjustment analysis for ports of Learning Type.

\begin{tabular}{lllll}
\hline Container ports & Container Berth & No. of pieces of equipment & Total quay length (m) & Terminal area (ha) \\
\hline Hongkong & $-72.64 \%$ & $-59.53 \%$ & $-51.34 \%$ & $-51.34 \%$ \\
Dubai & $-72.18 \%$ & $-87.54 \%$ & $-68.10 \%$ & $-68.10 \%$ \\
Rotterdam & $-65.82 \%$ & $-91.58 \%$ & $-66.93 \%$ & $-94.02 \%$ \\
Port Klang & $-49.33 \%$ & $-63.36 \%$ & $-49.33 \%$ & $-75.92 \%$ \\
Antwerp & $-66.05 \%$ & $-66.05 \%$ & $-71.45 \%$ & $-66.66 \%$ \\
Los Angeles & $-71.26 \%$ & $-74.50 \%$ & $-71.26 \%$ & $-76.98 \%$ \\
Hamburg & $-74.61 \%$ & $-74.61 \%$ & $-74.61 \%$ & $-82.70 \%$ \\
Long Beach & $-78.23 \%$ & $-64.02 \%$ & $-64.02 \%$ & $-82.61 \%$ \\
Average & $-68.77 \%$ & $-72.65 \%$ & $-64.63 \%$ & $-74.79 \%$ \\
\hline
\end{tabular}

average reductions of all inputs in "Learning Type" are much higher than this value. Among them, the highest proportion with $74.79 \%$ reduction ratio exists in the waste of terminal area resources of each port. Meanwhile, to provide more clear adjustment directions for each container port, this study has marked the highest reduction ratio for all DMUs in both Tables 3 and 4. To "Modesty Type", half of the ports (Busan, Kaohsiung, and Xiamen) present an urgent need to reduce the number of pieces of equipment in the port, while the demands for avoiding the waste of terminal area resource ranks in the second. However, this situation is reversed in "Learning Type". Over $62.5 \%$ of the container ports need to allocate terminal area resources more reasonable, and the highest reduced proportion is $94.02 \%$.

\section{Concluding remarks}

The "One Belt And One Road" initiative refers to the establishment of a number of bilateral mechanisms by the Chinese government based on economic and trade agreements with relevant countries, which has promoted to construct some effective regional cooperation platforms to achieve mutual benefit and win-win situation among the different partner countries. In addition, from the perspective of the development trend of global container ports, the intelligent transformation of ports is an inevitable trend of innovation and upgrading for all ports around the world. Driven by emerging technologies such as the blockchain, Internet of things (IOT), big data and artificial intelligence, the pressure for survival and development of smart port and city integration, as well as the competition from adjacent ports, is increasing. The shipping transport industry is considered a pillar of the economy country, particularly in some coastal states, and the growth of the East Asian container ports has been driven by the globalization of the world economy and the rise of China as the world's manufacturing center [33]. Ports on other continents, therefore, could set representative container ports in Asia as the benchmarks and study the operating ideas or experiences in marketing. Therefore, this study hopes to explore the division of the new pattern in the international container transport market based on the implementation of "One Belt And One Road" initiative, and help inefficient container ports to find the most appropriate benchmark to learn from the operation management experience.

In this study, we find that the container transport market is still mainly focused on Asian. At the same time, relatively efficient ports are gathered in regions such as the Yangtze River delta. By the influence of the implementation of "One Belt And One Road" initiative, the intelligent upgrade and transformation of Ningbo-Zhoushan port is accelerated through the resource reintegration, which has also help them create more annual output income. Tianjin port and Qingdao port, as pilot ports of "One Belt And One Road" initiative, have also gained some satisfactory benefits with the high operation performance in the global container transport market. Further, this study constructs a new reclassification for clustering world's top container ports. Based on the optimal adjustment analysis, ports affiliated to the "Modesty Type" should pay more attention to the utilization of equipment in the port, while the waste of terminal area resources is explored to be most critical potential problem for ports in "Learning Type". Learning the operation management experience from efficient container ports in Asia would be a smart choice for some inefficient ports. High efficient policy measures may lead to the promotion of potential business opportunities.

\section{Acknowledgements}

This research is partially supported by the natural science research project of university in Jiangsu (19KJB120009), and National Natural Science Foundation of China (No. 71801133). The author is also grateful to the comments and suggestions provided by anonymous reviewers. 


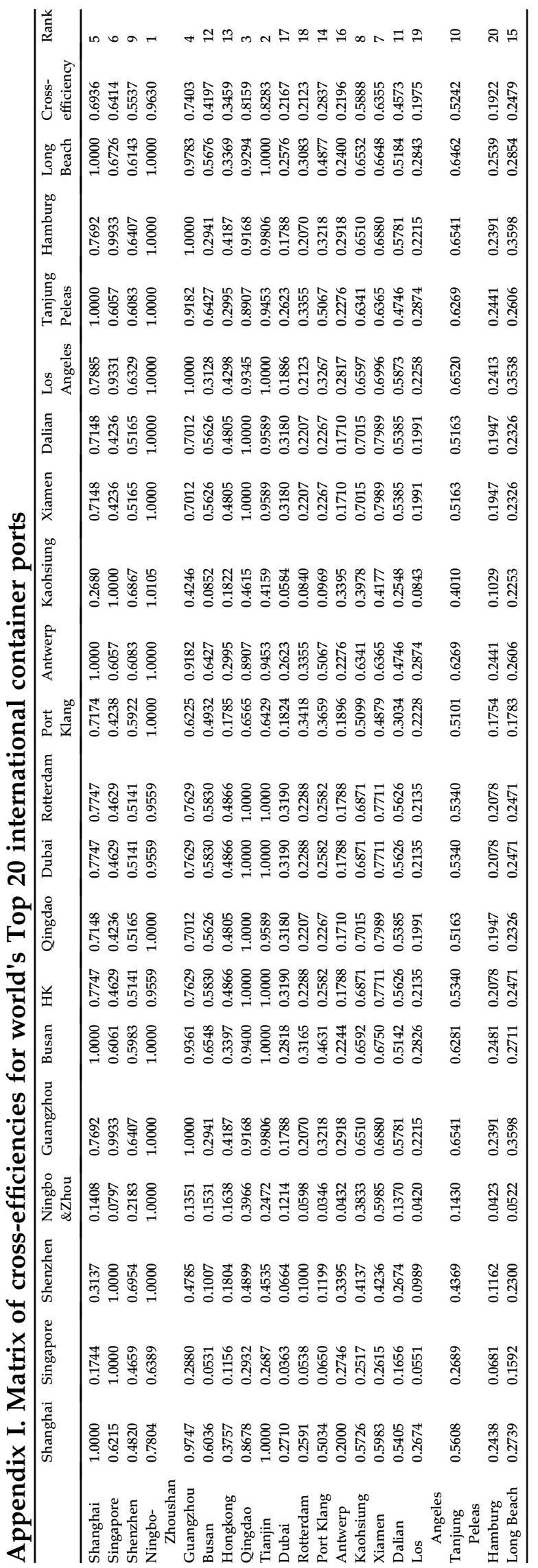

\section{References}

[1] Zarbi S, Shin SH, Shin YJ. An analysis by window DEA on the influence of international sanction to the efficiency of Iranian container ports. Asian J Ship Logist 2019;35(4): $163-71$.

[2] Shao ZZ, Ma ZJ, Sheu JB, Gao HO. Evaluation of large-scale transnational high-speed railway construction priority in the belt and road region. Transport Res E Logist Transport Rev 2018;117:40-57.

[3] Zeng Q, Wang GW, Qu C, Li KX. Impact of the Carat Canal on the evolution of hub ports under China's Belt and Road initiative. Transport Res E Logist Transport Rev 2018;117: 96-107.

[4] Wang W, Zhou Y, Song X, Tang G, Fang Z. Operational impact estimation of container inspections at dalian port: The application of simulation. Simulation 2017;93(2):135-48.

[5] Liu X, Zhang K, Chen B, Zhou J, Miao L. Analysis of logistics service supply chain for the One Belt and One Road initiative of China. Transport Res E Logist Transport Rev 2018;117: 23-39.

[6] Chen H, Cullinane K, Liu N. Developing a model for measuring the resilience of a port-hinterland container transportation network. Transport Res E Logist Transport Rev 2017;97:282-301.

[7] Clark X, Dollar D, Micco A. Port efficiency, maritime transport costs, and bilateral trade. J Dev Econ 2004;75(2):417-50.

[8] Liao W, Santacreu AM. The trade comovement puzzle and the margins of international trade. J Int Econ 2015;96(2): 266-88.

[9] Wiegmans B, Witte P, Spit T. Characteristics of european inland ports: A statistical analysis of inland waterway port development in Dutch municipalities. Transport Res Pol Pract 2015;78:566-77.

[10] Ha MH, Yang Z, Lam JSL. Port performance in container transport logistics: A multi-stakeholder perspective. Transport Pol 2019;73:25-40.

[11] Nguyen PN, Woo SH, Beresford A, Pettit S. Competition, market concentration, and relative efficiency of major container ports in Southeast Asia. J Transport Geogr 2020;83: 102653.

[12] Kaliszewski A, Kozłowski A, Dąbrowski J, Klimek H. Key factors of container port competitiveness: A global shipping lines perspective. Mar Pol 2020:103896.

[13] Li KX, Lin KC, Jin MJ, Yuen KF, Yang ZZ, Xiao Y. Impact of the belt and road initiative on commercial maritime power. Transport Res Pol Pract 2020;135:160-7.

[14] Charnes A, Cooper WW, Rhodes E. Measuring the efficiency of decision making units. Eur J Oper Res 1978;2(6):429-44.

[15] Zhou X, Pedrycz W, Kuang Y, Zhang Z. Type-2 fuzzy multiobjective DEA model: An application to sustainable supplier evaluation. Applied Soft Computing 2016;46:424-40.

[16] Gan GY, Lee HS, Chung CC, Chen SL. Performance evaluation of the security management of Changjiang maritime safety administrations: Application with undesirable outputs in data envelopment analysis. J Mar Sci Technol 2017;25(2): 213-9.

[17] Zhou Z, Xiao H, Jin O, Liu W. DEA frontier improvement and portfolio rebalancing: An application of China mutual funds on considering sustainability information disclosure. Eur J Oper Res 2018;269(1):111-31.

[18] Wegener M, Amin GR. Minimizing greenhouse gas emissions using inverse DEA with an application in oil and gas. Expert Systems with Applications 2019;122:369-75.

[19] Shwartz M, Burgess Jr JF, Zhu J. A DEA based composite measure of quality and its associated data uncertainty interval for health care provider profiling and pay-for-performance. Eur J Oper Res 2016;253(2):489-502.

[20] Arjomandi A, Dakpo KH, Seufert JH. Have asian airlines caught up with European airlines? A by-production efficiency analysis. Transport Res Pol Pract 2018;116:389-403. 
[21] Aparicio J, Cordero JM, Ortiz L. Measuring efficiency in education: The influence of imprecision and variability in data on DEA estimates. Socio-Economic Planning Sciences 2019;68:100698.

[22] Fukuyama H, Matousek R, Tzeremes NG. A nerlovian cost inefficiency two-stage DEA model for modeling banks' production process: Evidence from the Turkish banking system. Omega 2020:102198.

[23] Ouyang W, Yang JB. The network energy and environment efficiency analysis of 27 OECD countries: A multiplicative network DEA model. Energy 2020:117161.

[24] Chang V, Tovar B. Metafrontier analysis on productivity for west coast of south pacific terminals. Transport Res Pol Pract 2017;103:118-34.

[25] Wiegmans B, Witte P. Efficiency of inland waterway container terminals: Stochastic frontier and data envelopment analysis to analyze the capacity design- and throughput efficiency. Transport Res Pol Pract 2017;106: 12-21.

[26] Chen C, Lam JSL. Sustainability and interactivity between cities and ports: A two-stage data envelopment analysis (DEA) approach. Maritime Policy \& Management; 2018. p. $1-18$.

[27] Sun J, Yuan Y, Yang R, Ji X, Wu J. Performance evaluation of Chinese port enterprises under significant environmental concerns: An extended DEA-based analysis. Transport Pol 2017;60:75-86.

[28] Lin Y, Yan L, Wang YM. Performance evaluation and investment analysis for container port sustainable development in China: An inverse DEA approach. Sustainability 2019;11(17):4617.

[29] Wang Z, Wu X, Guo J, Wei G, Dooling TA. Efficiency evaluation and PM emission reallocation of China ports based on improved DEA models. Transport Res Transport Environ 2020;82:102317.

[30] Banker RD, Charnes A, Cooper WW. Some models for estimating technical and scale inefficiencies in data envelopment analysis. Manag Sci 1984;30(9):1078-92.

[31] Doyle J, Green R. Efficiency and cross-efficiency in DEA: Derivations, meanings and uses. J Oper Res Soc 1994:567-78.

[32] Sexton TR, Silkman RH, Hogan AJ. Data envelopment analysis: Critique and extensions. N Dir Progr Eval 1986; 1986(32):73-105.

[33] Hung SW, Lu WM, Wang TP. Benchmarking the operating efficiency of Asia container ports. Eur J Oper Res 2010;203(3): 706-13.

[34] Haralambides H, Gujar G. On balancing supply chain efficiency and environmental impacts: An eco-DEA model applied to the dry port sector of India. Marit Econ Logist 2012;14(1):122-37.

[35] Díaz-Hernández JJ, Martínez-Budría E, Salazar-González JJ. Measuring cost efficiency in the presence of quasi-fixed inputs using dynamic data envelopment analysis: The case of port infrastructure. Maritime Economics \& Logistics 2014; 16(2):111-26.

[36] Yu MM, Chen LH. Centralized resource allocation with emission resistance in a two-stage production system: Evidence from a Taiwan's container shipping company. Transport Res Pol Pract 2016;94:650-71. 